See Article page $\mathrm{XXX}$.

\section{Commentary: May the force(s) be with you: Loading conditions and the aorta}

Gerhard A. Holzapfel, PhD, ${ }^{\mathrm{a}, \mathrm{b}}$ Abe DeAnda, Jr, MD, and Keshava Rajagopal, $\mathrm{MD}, \mathrm{PhD}^{\mathrm{d}}$

Advances in diagnostic imaging, anesthetic and postoperative management, and significant developments in endovascular techniques, have expanded the pool of patients with treatable aortic disease. The current no man's land for endovascular surgery is the zone zero aorta, the region from the aortic annulus to the innominate artery origin. Understanding the biomechanics of this region could aid in conquering this zone.

Durbak and other Multidisciplinary Study of Ascending Tissue Characteristics and Hemodynamics for the Development of Novel Aortic Stentgrafts investigators ${ }^{1}$ provide a comprehensive analysis of zone zero aortic biomechanical properties. This study used the elastic energy stored in the aortic tissue to better identify and characterize regional variations along zone zero. The main finding was that the elastic energy varies significantly along the ascending aorta and the calculated energy decreases with age. Using the elastic energy to characterize an elastic material, including soft biological tissue, is an established approach in solid (bio)mechanics. There is a clear relationship between age and distensibility (elastic energy) of tissue samples, the older the age, the lower the distensibility, as previously

From the anstitute of Biomechanics, Graz University of Technology, Graz, Austria; ${ }^{\mathrm{b}}$ Department of Structural Engineering, Norwegian University of Science and Technology, Trondheim, Norway; ' Division of Cardiovascular and Thoracic Surgery, Department of Surgery, University of Texas Medical Branch-Galveston, Galveston, Tex; and ${ }^{\mathrm{d}}$ Department of Clinical Sciences, University of Houston College of Medicine, Houston, Tex.

Disclosures: The authors reported no conflicts of interest.

The Journal policy requires editors and reviewers to disclose conflicts of interest and to decline handling or reviewing manuscripts for which they may have a conflict of interest. The editors and reviewers of this article have no conflicts of interest.

Received for publication Oct 1, 2021; revisions received Oct 1, 2021; accepted for publication Oct 4, 2021.

Address for reprints: Abe DeAnda, Jr, MD, Division of Cardiovascular and Thoracic Surgery, University of Texas Medical Branch-Galveston, 301 University Blvd, Galveston, TX 77551 (E-mail: abdeanda@utmb.edu).

J Thorac Cardiovasc Surg 2021; $\mathbf{\square}: 1-2$

0022-5223/\$36.00

Copyright (c) 2021 Published by Elsevier Inc. on behalf of The American Association for Thoracic Surgery

https://doi.org/10.1016/j.jtcvs.2021.10.002

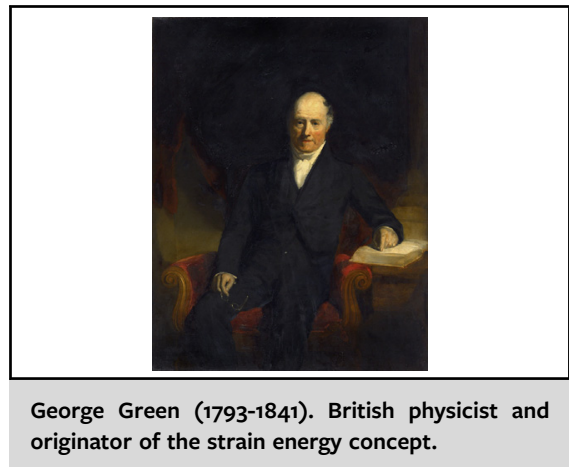

CENTRAL MESSAGE

State-of-the-art experimental studies of aortic mechanics may have important implications for the endovascular treatment of aortic diseases.

shown for aged human iliac arteries. ${ }^{2}$ The authors used an inflection point from which the elastic energy was calculated. Our primary comments regarding this study are as follows:

- The term inflection point is misleading. By definition, an inflection point is a point at which the curvature changes sign. Instead, this inflection point was defined as a transition from a low-stiffness (stiffness being the ratio of stress to strain) range of strains to a high-stiffness range. Such transitions cannot be seen in the plots of the article because the curvature in all stress-strain curves transitions gradually.

- As defined, the circumferential normal stress at the inflection point almost always appears to be below the $100 \mathrm{kPa}$ level, which is well below the stress level present at physiological range mean arterial pressure, so no conclusion can be drawn on this basis.

- The elastic strain energy is equal to the integral of stress through strain; that is, the area under the stress-strain relationship. However, there is no apparent reason why the authors chose the so-called inflection point strain as the upper bound for the integration to calculate the strain energy.

- Such an approach results in some energy stored in the aortic segment, but certainly not in the correct elastic energy because this is not a 1-dimensional problem. The biaxial tests carried out can also be used to determine longitudinal normal stress. Thus, strains occur in the 
circumferential and axial direction, and due to incompressibility (constant density when subjected to loading), the strain in the radial direction can also be calculated (it is a 3-dimensional problem). It is then possible to derive the strain energy from the full set of strains. This could be done by fitting the experimentally obtained data to an anisotropic material equation to obtain the material properties, and then the strain energy ${ }^{3}$ (elastic energy stored in the tissue) can be calculated for a certain state of physiological strains. These scalar measures can then be compared with each another on a reliable theoretical basis.
Despite these technical misgivings, the authors are to be congratulated on this innovative approach. Studies such as this are critical in understanding the tissue properties of the aorta.

\section{References}

1. Durbak E, Tarraf S, Gillespie C, et al. Ex vivo biaxial load testing analysis of aortic biomechanics demonstrates variation in energy distribution across aortic zone zero. J Thorac Cardiovasc Surg. 2021. XXX:XXX.

2. Schulze-Bauer CAJ, Mörth C, Holzapfel GA. Passive biaxial mechanical response of aged human iliac arteries. J Biomech Eng. 2003;125:395-406.

3. Holzapfel GA. Nonlinear Solid Mechanics. A Continuum Approach for Engineering. John Wiley \& Sons; 2000. 